\title{
Ovarian Ectopic Pregnancy: A Report of Two Cases with Variable Presentation
}

\author{
Renuka Verma*, Veena Gupta, Promil Jain, Meenu Gill, Sumiti Gupta \\ UHS Rohtak, India
}

Submission: May 05, 2017; Published: August 30, 2017

*Corresponding author: Renuka Verma, UHS Rohtak, H.no.138-1, model town, India, Tel: 8295953200; Email: renuka138pathology@gmail.com

\begin{abstract}
Ovarian pregnancy is one of the rarest variants of ectopic implantation. It is often difficult to distinguish clinically from tubal pregnancy, and diagnosis and management are frequently a challenge. Patients frequently present with amenorrhea and acute abdominal pain. A diagnostic delay may lead to rupture, secondary implantation or operative difficulties. Therefore, awareness of this rare condition is important in reducing the associated risks. Here, we report two cases of primary ovarian pregnancies one presenting with acute abdominal pain, and other misdiagnosed as tubal pregnancy. Both cases were confirmed by histopathological examinations and were successfully managed by surgery.

Keywords: Ovarian; Ectopic pregnancy; Histopathology
\end{abstract}

\section{Introduction}

Ectopic Pregnancy is an important health problem and accounts for $10 \%$ of maternal mortality [1]. Ovarian pregnancy is even rarer accounting for $0.15-3 \%$ of all ectopic gestations [2]. The diagnosis of ovarian pregnancy is difficult and seldom made before surgery. Ultrasound, especially transvaginal scanning (TVS) has proved to be an invaluable tool in the diagnosis of this condition. Here we report two cases of ovarian pregnancies which are further add to the reported literature.

\section{Case Presentation}

\section{Case 1}

A 32 years old female, with a history of 6 weeks amenorrhea, complained of severe left sided lower abdominal pain. There was no history of vaginal bleeding, difficulty in micturition or defaecation. There were no signs and symptoms of circulatory instability. The patient had two previous full term normal vaginal deliveries. The last child birth was two years ago and she was using intrauterine device since then.

Vaginal examination revealed tenderness in the fornices, with mild neutrophilic leucocytosis on routine haematological test. The clinical diagnosis of pelvic inflammatory disease or tuboovarian mass was made. Abdominal ultrasound revealed free fluid in pouch of douglas but no intrauterine sac. On laprotomy left ovary was enlarged, right ovary and both sided fallopian tubes seemed to be unremarkable. Left salpingo-oophorectomy with right sided tubal ligation was performed and the sample was received in pathology.

On gross examination, the ovary measured $4.0 \times 3.3 \times 2.0 \mathrm{~cm}$, cut section was tan revealed blood clots and no embryo was detected grossly. The fallopian tube measured $4.0 \mathrm{~cm}$ and was unremarkable with patent lumen. On microscopic examination, fallopian tubes were unremarkable and sections from ovary revealed chorionic villi lying dispersed within ovarian stroma (Figure 1a \& 1b).

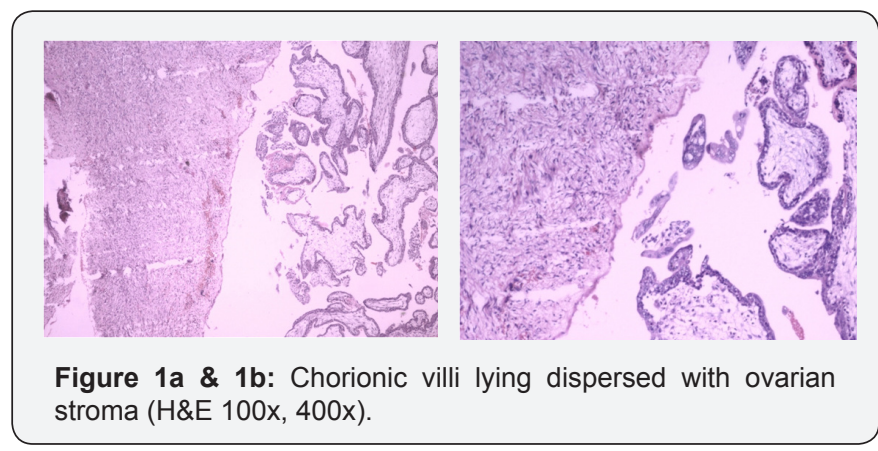

\section{Case 2}

A 24 years old nulliparous female, presented with severe pain in bilateral lower abdomen and mild vaginal bleeding for one day. She reported a history of amenorrhea of 2 months, and her previous menstrual cycles were regular. She did not give 
any history of sexually transmitted disease, pelvic inflammatory disease, or previous gynecological surgery.

There was rebound tenderness in the abdomen during physical examination. The patient's pulse rate was $90 / \mathrm{min}$, and blood pressure 90/60 mmHg. Haemoglobin levels were $8.0 \mathrm{~g} / \mathrm{dL}$. Urine for pregnancy test was positive. Transvaginal ultrasound (TVS) examination showed an empty uterus, corpus luteum in the left ovary and a $22 \mathrm{~mm}$ hyperechoic mass with a central hypoechoic shadow in the left adnexa, suggesting a tubal pregnancy. The right adnexa was normal, a large amount of fluid in the cul-de-sac and abdominal cavity was observed. Emergency laparotomy was performed and active bleeding was observed from the left ovary which was suggestive of ruptured ectopic pregnancy and around $300 \mathrm{ml}$ of blood was evacuated from abdominal cavity. The left fallopian tube appeared to be normal.

Wedge excision of the haemorrhagic mass of the left ovary was done and the specimen was received for histopathological examination. On Gross examination, the ovary measured $4.2 \times 3.0 \times 1.0 \mathrm{~cm}$. The external surface as well as the cut surface was haemorrhagic. On microscopic examination, chorionic villi lying dispersed in a background of haemorrhagic ovarian stroma were identified (Figure 2).

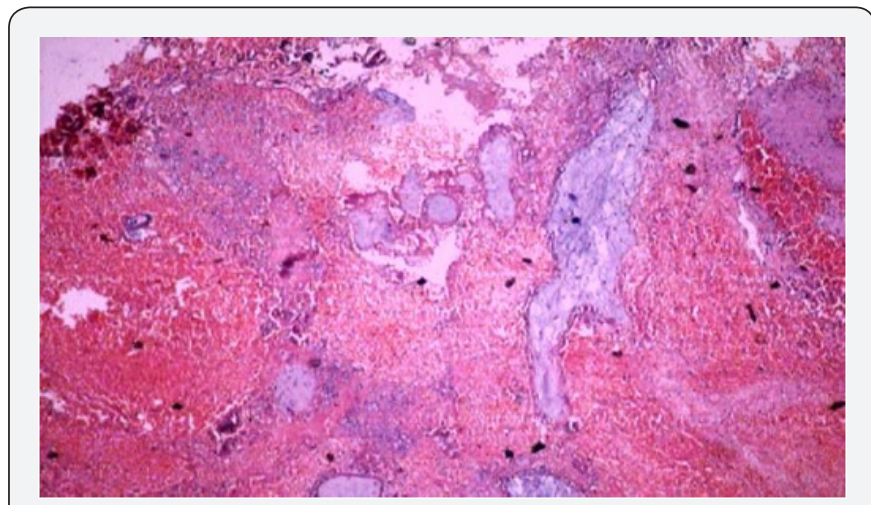

Figure 2: Ovarian stroma with scattered chorionic villi and extensive areas of haemorrhage (H\&E 200x).

\section{Discussion}

Ovarian pregnancy is a rare variant of ectopic pregnancy. Early diagnosis of ovarian pregnancy is necessary in order to avoid serious complications and emergency invasive procedures. The first case was reported by St. Maurice in 1682 [3]. The reported incidence is $0.15-3 \%$ of all ectopic gestations [2].

The four diagnostic criteria, all of which must be met before a pathological diagnosis of ovarian pregnancy can be made, laid down by Spiegelberg in 1878 are as follows: The tube on the affected side must be intact, the gestational sac must be present in the ovary, the ovary and gestational sac must be connected to the uterus by the utero-ovarian ligament (ligamentum proprium ovarii), definite ovarian tissue must be present in the sac wall [4]. No additions have been made to these criteria. Therefore this entity is defined as a pregnancy in which primary implantation has occurred in or on the ovary.

Ovarian pregnancy can be classified as primary and secondary; primary when ovum is fertilized while still within the follicle, secondary when fertilization takes place in the tube and the conceptus is later regurgitated to be implanted in the ovarian stroma. They can be intrafollicular or extrafollicular. Intrafollicular is invariably primary and extrafollicular may be primary or secondary where ovarian tissue is usually absent in the gestational sac [5].

The etiology of this condition is unknown, but the suggested causes can be enumerated as follows:

i. Obstruction to ovulation, ovarian fertilization and implantation which can be due to inflammation, adhesions, low intrafollicular pressure, tenacious granulosa cells and cumulus oophorus

ii. Inefficient tubal function (tubal fertilization and ovarian implantation-primary or after tubal abortion) which can be inflammatory or idiopathic

iii. Favourable surface phenomena (ovarian fertilization and implantation) including decidual changes affecting the ovary, ovarian endometriosis and ectopic mullerian duct epithelium

iv. Parthenogenesis

v. Chance [6].

Reported risk factors include previous pelvic inflammatory disease, endometriosis, assisted reproductive technologies and IUD use [7]. In a study of six cases of ovarian pregnancy, Comstock et al found abdominal pain and light vaginal bleeding to be common presenting symptoms [8]. Ovarian pregnancies can be mistaken for a hemorrhagic corpus luteum cysts, in one of the case it was misdiagnosed as tubal ectopic. Ovarian pregnancies usually terminate in rupture during the first trimester in $91.0 \%$ cases, $5.3 \%$ in second trimester and $3.7 \%$ in third trimester [1]. Only one case has been reported in literature where ovarian pregnancy has progressed to full term delivery [9]. Both of our cases presented in 1 st trimester.

Treatment of ovarian pregnancy usually requires oophorectomy or wedge resection of the ovary. If future fertility is desired, wedge resection is considered. Oophorectomy should be reserved for cases of advanced gestation. Medical management with methotrexate may be an option if there is persistent trophoblastic tissue after laparotomy [10].

\section{Conclusion}

Although ovarian pregnancy is a rare event and is difficult to diagnose, awareness of this condition is important in reducing the associated morbidity and mortality. Hence, it can be concluded that ovarian ectopic pregnancy should be entertained as one of the important differential diagnosis in a female of reproductive age group presenting with acute abdomen. 


\section{References}

1. Das S, Kalyani R, Lakshmi M (2008) Ovarian Pregnancy. Indian J Path Microbiol 51(1): 37-38.

2. Nwanodi O, Khulpateea N (2006) Primary Ovarian Pregnancy. Journal of the National Medical Association 98(5): 797.

3. Mehmood SA, Thomas JA (1985) Primary ectopic ovarian pregnancy (report of three cases). J Postgrad Med 31: 219.

4. Spiegelberg O (1878) Zur Casuistic der Ovarialschwangerschaft. Arch Gynaekol 13: 73.

5. Gon S, Majumdar B, Ghosal T, Sengupta M (2011) Two Cases of Primary Ectopic Ovarian Pregnancy. Online J Health Allied Scs 10(1): 26.
6. Shatz RM, Davis BA, Gelfand MM (1969) Primary ovarian ectopic pregnancy. Canad Med Ass J 100: 959-960.

7. Molinaro TA, Barnhart KT (2007) Ectopic pregnancies in unusual locations. Semin Reprod Med 25(2): 123-130.

8. Comstock C, Huston K, Lee W (2005) The ultrasonographic appearance of ovarian ectopic pregnancies. Obstet Gynecol 105(1): 42-46.

9. William PC, Machar TC, Icneft JR (1982) Term ovarian pregnancy with delivery of female infant. Am J Obstet Gynecol 142: 1589-1591.

10. Seinera P, DiGregorio A, Arisio R, Decko A, Crana F (1997) Ovarian pregnancy and operative laparoscopy: report of eight cases. Hum Reprod 12(3): 608-610.

\section{Your next submission with Juniper Publishers} will reach you the below assets

- Quality Editorial service

- Swift Peer Review

- Reprints availability

- E-prints Service

- Manuscript Podcast for convenient understanding

- Global attainment for your research

- Manuscript accessibility in different formats

( Pdf, E-pub, Full Text, Audio)

- Unceasing customer service

Track the below URL for one-step submission https://juniperpublishers.com/online-submission.php 